\title{
EDITORIAL
}

\section{The present status of anorexia nervosa ${ }^{1}$}

During the past decade there has been a spate of research articles on anorexia nervosa. One reason for this is probably that the illness has been recognized much more frequently in recent years (Theander, 1970) or perhaps that it has actually increased in its incidence (Kendell et al. 1973). There is also the advantage that anorexia nervosa is one of the few psychiatric disorders that lends itself readily to being accorded clear-cut diagnostic criteria. These have been expressed in terms of necessary criteria where all the stipulated requirements must be satisfied (Russell, 1970), or in terms of quantitative criteria where a given proportion of possible abnormalities or a certain degree of disturbance, such as the amount of weight loss, should be present (Feighner et al. 1972). The former approach would appear to be preferable, but the latter can at least serve the purpose of providing operational definitions of value in clinical research. Finally, anorexia nervosa allows the researcher to study simultaneously disturbances of mental and bodily function, so enabling him to observe their complex interaction. It is appropriate, therefore, to refer in turn to studies that have concentrated on the psychological aspects of the illness and on its physical aspects. An attempt will also be made to synthesize the findings of these studies - by no means an easy task.

Evidence for anorexia nervosa having a psychological origin is not hard to come by. The patients tell us that they do not eat normally because they are fearful of becoming fat or of losing control over eating, or that they experience unpleasant feelings of guilt after having eaten. In 1962 Hilde Bruch suggested that these patients show a disturbance of their body image marked by indifference to their emaciation which they defend as normal and right. She has pointed out that the denial of their thinness is pathognomonic of anorexia nervosa (Bruch, 1974). Recently, experimental evidence has supported the presence of a perceptual disorder. Wasted patients, when asked to estimate their body size, tend to indicate that they see themselves as wider than they actually are, and wider indeed than the configuration of a normally proportioned woman. Different methods of measurement have been used: a size-estimation bar carrying lights whose separation was taken as the estimate of body width (Slade \& Russell, 1973) or the presentation to the patients of photographs of themselves enlarged or diminished by means of a special lens (Meyer \& Tuchelt-Gallwitz, 1968; Garner et al. 1977). In general, there has been agreement that patients with anorexia nervosa see themselves as abnormally wide and fat (Crisp \& Kalucy, 1974; Goldberg et al. 1977). Some investigators have found that the perceptual disturbance is sensitive to the patient's eating pattern and becomes worse after a meal (Crisp \& Kalucy, 1974). Others report that the disturbance becomes diminished if the patient gains weight as a result of treatment (Slade \& Russell, 1973): herein lies the paradox that gaining weight has the effect of reducing the patient's view of herself as a fat person. In another experimental study, patients with anorexia nervosa were found, in contrast with normal subjects, to vary their food intake according to their own awareness of body size: when they were deceived into believing that they had gained weight, they ate less, and vice versa (Russell et al. 1975). It was concluded that in these patients body weight is not regulated readily by normal physiological mechanisms but is more at the mercy of external cues of body size. The findings of these studies may be combined. Food intake in anorexia nervosa is unduly dependent on the patient's awareness of her body size; as this awareness is a distorted one in the direction of seeing herself as unduly large, it follows that the patient will starve herself in an attempt to return to what she considers to be more normal proportions. Yet the starvation and weight loss may worsen the distorted awareness of herself. Here, therefore, is a basis for the self-perpetuation of anorexia nervosa. Thus, clinical observations supplemented by experimental studies confirm - if any confirmation was needed - that abnormal attitudes to eating and body size are responsible for the illness or at least for its perpetuation. Such a view has been prevalent since the first descriptions of anorexia nervosa which was attributed by Gull in 1874 to a morbid state of mind.

\footnotetext{
1 Address for correspondence: Professor G. F. M. Russell, Royal Free Hospital, Pond St., London NW3 2 QG. 
As regards the physical aspects of anorexia nervosa the hypothesis has been put forward that the illness is in part due to a disorder of hypothalamic function (Russell, 1965, 1972a). Support for this hypothesis has come from a number of studies which have been concerned with the control of water balance, thermo-regulation, and especially the endocrine status of patients with anorexia nervosa (Warren \& Vande Wiele, 1973; Mecklenburg et al. 1974; Boyar et al. 1974; Garfinkel et al. 1977). The question is a complicated one. It is probably fair to consider several of the bodily disturbances found in malnourished patients with anorexia nervosa as depending for their pathogenesis on a disorder of hypothalamic function. But most of these disturbances are a direct consequence of the patient's malnutrition, and clear up rapidly if she can be persuaded to return to a healthy weight or if she recovers spontaneously. For example, elevated blood levels of growth hormone, originally observed by Landon et al. (1966), have been shown by Brown et al. (1977) to return rapidly to normal in patients whose caloric intake has improved. On the other hand, defects of thermo-regulation persist longer and require that the patient's weight returns fully to normal, but in this example also it is probable that the defects of temperature control are directly caused by malnutrition, including the loss of protective subcutaneous fat (Wakeling \& Russell, 1970). Much more interesting are the observations that correction of the patient's weight loss fails, in the short term at least, to reverse the intricate hormonal disturbances affecting the hypothalamic-pituitary-gonadal axis. In normal subjects there is a complex circular interaction between the hypothalamus, the anterior pituitary and the gonads. Gonadotrophin-releasing hormones originate from the hypothalamus and discharge the gonadotrophins (luteinizing hormone (LH) and follicle-stimulating hormone (FSH)) from the anterior pituitary gland. The gonadotrophins cause oestrogens and progesterone to be secreted by the ovaries. Oestrogens and progesterone in turn exert negative and positive feedback effects on the hypothalamus and the anterior pituitary. In severe anorexia nervosa, urinary and blood levels of gonadotrophins (FSH and LH) and oestrogens are always low or undetectable (Russell et al. 1965; Bell et al. 1966; Crisp et al. 1973). Moreover, there is evidence of a diminished release of LH following the administration of one of the following substances: synthetic gonadotrophin-releasing hormone, clomiphene (a synthetic drug used in the treatment of anovular infertility), or ethinyl oestradiol. Under appropriate circumstances these substances are likely to cause elevation of blood LH levels in normal menstruating women. Synthetic gonadotrophin-releasing hormone discharges FSH and LH if these are present in the anterior pituitary stores. Clomiphene is thought to act by blocking the negative feedback effects of oestrogens on the hypothalamus. Ethinyl oestradiol owes its effect to a positive feedback action that is only evident after a short (3-day) course of the drug, a negative feedback effect predominating during the actual period of its administration. In the undernourished patient all these responses are absent or much diminished. If, however, the patient can be persuaded to eat so that her weight returns to normal, many of these hormonal disturbances are gradually reversed. For example, urinary and blood levels of gonadotrophins (LH and FSH) and oestrogens gradually rise (Russell \& Beardwood, 1968; Crisp et al. 1973). On the other hand, these levels do not readily fluctuate in a cyclical fashion such as would herald a resumption of regular menstruation. Among the tests of responsiveness of $\mathrm{LH}$ to different substances, the action of gonadotrophin-releasing hormone is most readily restored to normal, establishing that there is a rapid return of the functional capacity of the anterior pituitary (Sherman et al. 1975; Brown et al. 1977). The response to clomiphene may also return (Marshall \& Russell Fraser, 1971; Beumont et al. 1973; Wakeling et al. 1976; Brown et al. 1977), but some patients show only an incomplete response even though their weight has been restored to normal (Wakeling et al. 1976). The most significant findings are the negative and positive feedback effects of administered oestrogen on $\mathrm{LH}$ release in patients whose weight has become normal. Although the negative feedback effects are soon restored, the positive feedback release of $\mathrm{LH}$ following a 3-day course of ethinyl oestradiol returns in only a small proportion of the patients (Wakeling et al. 1977a, 1977b). This finding indicates a more persistent abnormality in the hypothalamic regulation of gonadotrophin release, and confirms an earlier view that the specific endocrine disturbance in anorexia nervosa is dependent only in part on the patient's loss of weight and malnutrition (Russell \& Beardwood, 1968).

The research findings on disturbances of the hypothalamic-pituitary-gonadal axis assume a 


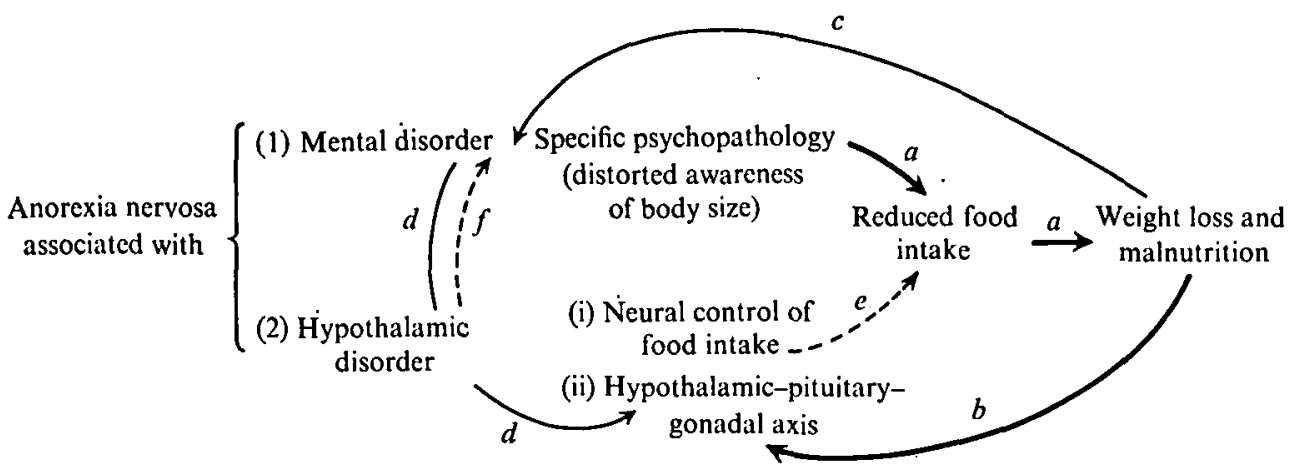

Fig. 1.

considerable significance, for they cannot simply be interpreted as a consequence of the malnutrition of anorexia nervosa. They must indicate a more fundamental disorder of hypothalamic function. Moreover, they are directly relevant to a salient clinical phenomenon, namely the cessation of spontaneous menstruation, which is one of the necessary diagnostic features of anorexia nervosa. Finally, these findings are in keeping with early clinical observations that amenorrhoea may be an early event in the course of the illness preceding any loss of weight (Kay \& Leigh, 1954), and persisting in a minority of patients in spite of maintaining a normal weight over a period of several months or even years. A cautionary note must be sounded. An individual patient's responsiveness of LH to clomiphene or ethinyl oestradiol has been of little value in predicting the outcome of her illness. It may have served to predict the imminence of a return of menstruation, but no more than this. Neither does it seem to be correlated with the patient's psychological recovery, a full LH response to administered oestrogen being compatible with persistence of the mental disturbances characteristic of anorexia nervosa.

How do recent researches help us to decide whether a disorder of hypothalamic function is relevant to the genesis of anorexia nervosa? What follows is necessarily a simplistic discussion of a most baffling problem. Endocrinologists, who have the merit of seeing the issues in black-and-white terms, have put forward 3 possibilities (Mecklenberg et al. 1974):

(1) weight loss 'damages' the hypothalamus;

(2) the mental disturbance, or those events that are considered of psychogenic importance ('psychic stress'), interfere with hypothalamic function;

(3) the endocrine manifestations and the psychopathological features are relatively independent expressions of a primary hypothalamic defect of unknown aetiology.

At the risk of appearing even more naïve, but in an attempt to clarify the issues and to sum up the evidence so far, a flow diagram (Fig. 1) is presented which emphasizes the circular interactions between the psychological disorder, the endocrine disturbances and the malnutrition. The thickness of the lines reflects the weight of evidence supporting each interaction. Firmly established is the pathway that attributes to the mental disorder the reduced food intake and loss of weight (a), which in turn cause the endocrine disturbance and amenorrhoea $(b)$. It is also probable that the weight loss and malnutrition aggravate the mental disorder in the manner discussed earlier $(c)$. The literature on the effects of emotional upheavals and mental illness in causing amenorrhoea also supports a direct pathway between mental and hypothalamic disorders in anorexia nervosa (d) (Drew, 1961 ; Russell, $1972 b$ ). Next, there is a possible link between a disorder in the hypothalamic control of food intake and the food refusal characteristic of anorexia nervosa $(e)$. It was this possibility which gave rise to the original hypothesis of anorexia nervosa being caused by a disorder of hypothalamic function. A final postulated link $(f)$ is that representing the neural effects of a hypothalamic disorder in moulding the patient's mental functions so as to give rise to her abnormal attitudes to eating, body size and sexuality. These last two links ( $e$ and $f$ ) are the weakest ones in the chain, for there is as yet no 
direct evidence in support of them. What is clear, however, is that self-perpetuating disturbances play an important part in anorexia nervosa.

In the absence of established causes and specific treatments, our therapeutic endeavours must depend on the interruption of these vicious circles. Short-term successes are most readily achieved by restoring body weight to normal and thus correcting malnutrition and its consequences (Russell, 1977). Even so, a substantial proportion of patients relapse, so that the regime of refeeding must be repeated on one or more occasions (Morgan \& Russell, 1975). It may be possible to reduce the number of relapses and shorten the overall course of the illness by means of skilled psychotherapy aimed at the psychopathology that is characteristic of anorexia nervosa (Thomä, 1967; Bruch, 1974), but it would be gratifying if a well-designed study established the efficacy of this treatment.

GERALD RUSSELL

\section{REFERENCES}

Bell, E. T., Harkness, R. A., Loraine, J. A. \& Russell, G. F. M. (1966). Hormone assay studies in patients with anorexia nervosa. Acta Endocrinologica 51, 140-148.

Beumont, P. J. V., Carr, P. J. \& Gelder, M. G. (1973). Plasma levels of luteinizing hormone and of immunoreactive oestrogens (oestradiol) in anorexia nervosa: response to clomiphene citrate. Psychological Medicine 3, 495-501.

Boyar, R. M., Katz, J., Finkelstein, J. W., Kapen, S., Weiner, H., Weitzman, E. D. \& Hellman, L. (1974). Anorexia nervosa: immaturity of the 24-hour luteinizing hormone secretory pattern. New England Journal of Medicine 291, 861-865.

Brown, G. M., Garfinkel, P. E., Jeuniewic, N., Moldofsky, H. \& Stancer, H. C. (1977). Endocrine profiles in anorexia nervosa. In Anorexia Nervosa (ed. R. A. Vigersky), pp. 123-135. Raven Press: New York (in the press).

Bruch, H. (1962). Perceptual and conceptual disturbances of anorexia nervosa. Psychosomatic Medicine 24, 187-194.

Bruch, H. (1974). Eating Disorders: Obesity, Anorexia Nervosa and the Person Within. Routledge and Kegan Paul: London.

Crisp, A. H. \& Kalucy, R. S. (1974). Aspects of the perceptual disorder in anorexia nervosa. British Journal of Medical Psychology 47, 349-361.

Crisp, A. H., Mackinnon, P. C. B., Chen, C. \& Corker, C. S. (1973). Observations of gonadotrophic and ovarian hormone activity during recovery from anorexia nervosa. Postgraduate Medical Journal 49, 584-590.

Drew, F. L. (1961). The epidemiology of secondary amenorrhoea. Journal of Chronic Diseases 14, 396-407.

Feighner, J. P., Robins, E., Guze, S. B., Woodruff, R. A., Winokur, G. \& Munoz, R. (1972). Diagnostic criteria for use in psychiatric research. Archives of General Psychiatry 26, 57-63.

Garfinkel, P. E., Moldofsky, H. \& Garner, D. M. (1977). The outcome of anorexia nervosa: significance of clinical features, body image and behaviour modification. In Anorexia Nervosa (ed. R. A. Vigersky), pp. 315-329. Raven Press: New York (in the press).

Garner, D. M., Garfinkel, P. E., Stancer, H. C. \& Moldofsky, H. (1977). Body image disturbances in anorexia nervosa and obesity. In Anorexia Nervosa (ed. R. A. Vigersky), pp. 27-30. Raven Press: New York (in the press).

Goldberg, S. C., Halmi, K. A., Casper, R., Eckert, E. \& Davis, J. M. (1977). Pretreatment predictors of weight gain in anorexia nervosa. In Anorexia Nervosa (ed. R. A. Vigersky), pp. 31-41. Raven Press: New York (in the press).

Gull, W: (1874). Anorexia nervosa (apepsia hysterica, anorexia hysterica). Transactions of the Clinical Society of London 7, 22-28.
Kay, D. W. K. \& Leigh, D. (1954). The natural history, treatment and prognosis of anorexia nervosa, based on a study of 38 patients. Journal of Mental Science 100, 411431.

Kendell, R. E., Hall, D. J., Hailey, A. \& Babigian, H. M. (1973). The epidemiology of anorexia nervosa. Psychological Medicine 3, 200-203.

Landon, J., Greenwood, F. C., Stamp, T. C. B. \& Wynn, V. (1966). The plasma sugar, free fatty acid, cortisol and growth hormone response to insulin, and the comparison of this procedure with other tests of pituitary and adrenal function. II. In patients with hypothalamic or pituitary dysfunction or anorexia nervosa. Journal of Clinical Investigation 45, 437-449.

Marshall, J. C. \& Russell Fraser, T. (1971). Amenorrhoea in anorexia nervosa: assessment and treatment with clomiphene citrate. British Medical Journal iv, 590-592.

Mecklenburg, R. S., Loriaux, D. L., Thompson, R. H., Andersen, A. E. \& Lipsett, M. B. (1974). Hypothalamic dysfunction in patients with anorexia nervosa. Medicine 53, 147-159.

Meyer, J. E. \& Tuchelt-Gallwitz, A. (1968). A study on social image, body image and the problem of psychogenetic factors in obesity. Comprehensive Psychiatry 9, $148-154$.

Morgan, H. G. \& Russell, G. F. M. (1975). Value of family background and clinical features as predictors of long. term outcome in anorexia nervosa: four-year follow-up study of 41 patients. Psychological Medicine 5, 355-371.

Russell, G. F. M. (1965). Metabolic aspects of anorexia nervosa. Proceedings of the Royal Society of Medicine 58, 811-814.

Russell, G. F. M. (1970). Anorexia nervosa: its identity as an illness and its treatment. In Modern Trends in Psychological Medicine, vol. 2 (ed. J. Harding Price), pp. 131-164. Butterworths: London.

Russell, G. F. M. (1972a). Premenstrual tension and 'psychogenic' amenorrhoea: psycho-physical interactions. Journal of Psychosomatic Research 16, 279-287.

Russell, G. F. M. (1972b). Psychological and nutritional factors in disturbances of menstrual function and ovulation. Postgraduate Medical Journal 48, 10-13.

Russell, G. F. M. (1977). General management of anorexia nervosa and difficulties in assessing the efficacy of treatment. In Anorexia Nervosa (ed. R. A. Vigersky), pp. 277289. Raven Press: New York (in the press).

Russell, G.F. M. \& Beardwood, C. J. (1968). The feeding disorders, with particular reference to anorexia nervosa and its associated gonadotrophin changes. In Endocrinology and Human Behaviour (ed. R. P. Michael), pp. 310-329. Oxford University Press: London.

Russell, G. F. M., Loraine, J. A., Bell, E. T. \& Harkness, R. A. (1965). Gonadotrophin and oestrogen excretion in patients with anorexia nervosa. Journal of Psychosomatic Research 9, 79-85. 
Russell, G. F. M., Campbell, P. G. \& Slade, P. D. (1975). Experimental studies on the nature of the psychological disorder in anorexia nervosa. Psychoneuroendocrinology 1 , $45-56$.

Sherman, B. M., Halmi, K. A. \& Zamudio, R. (1975). LH and FSH response to gonadotrophin-releasing hormone in anorexia nervosa: effect of nutritional rehabilitation. Journal of Clinical Endocrinology and Metabolism 41, 135-142.

Slade, P. D. \& Russell, G. F. M. (1973). Awareness of body dimensions in anorexia nervosa: cross-sectional and longitudinal studies. Psychological Medicine 3, 188-199.

Theander, S. (1970). Anorexia nervosa: a psychiatric investigation of 94 female cases. Acta Psychiatrica Scandinavica, Supplement 214.

Thomä, H. (1967). Anorexia Nervosa (trans. G. Brydone). International University Press: New York.

Wakeling, A. \& Russell, G. F. M. (1970). Disturbances in the regulation of body temperature in anorexia nervosa. Psychological Medicine 1, 30-39.
Wakeling, A., Marshall, J. C., Beardwood, C. J., De Souza, V. F. A. \& Russell, G. F. M. (1976). The effects of clomiphene citrate on the hypothalamic-pituitary-gonadal axis in anorexia nervosa. Psychological Medicine 6, 371-380.

Wakeling, A., De Souza, V. F. A. \& Beardwood, C. J. $(1977 a)$. Assessment of the negative and positive feedback effects of administered oestrogen on gonadotrophin release in patients with anorexia nervosa. Psychological Medicine 7, 397-405.

Wakeling, A., De Souza, V. F. A. \& Beardwood, C. J. $(1977 b)$. The effects of administered oestrogen on luteinizing hormone release in subjects with anorexia nervosa in acute and recovery stages. In Anorexia Nervosa (ed. R. A. Vigersky), pp. 199-209. Raven Press: New York (in the press).

Warren, M. P. \& Vande Wiele, R. L. (1973). Clinical and metabolic features of anorexia nervosa. American Journal of Obstetrics and Gynaecology 117, 435-449. 